\author{
María Barbaño González-Moreno \\ Universidad de Granada, Granada, Espanha
}

Luis D. Rivero Moreno

Universidad de Granada, Granada, Espanha

\title{
Carolee Schneemann. El cine como autobiografía, la artista como actriz, el cuerpo como pincel
}

\begin{abstract}
Resumen: Este trabajo analiza la relación de cine y mujer a partir de la obra fílmica de Carolee Schneemann, principalmente de su obra autobiográfica Fuses (1964-1966). Desde ella, se plantea el papel de la artista como productora, directora y protagonista principal de todas sus obras. Reflexionamos así sobre el rol del creador-director como actor que derivaría en la consecución de una obra cinematográfica de tintes necesariamente autobiográficos. Asumiendo la visión vanguardista del cine como diario personal/Entendido el cine como diario personal, Schneemann va a explorar en su obra diferentes aspectos de la identidad y la sexualidad de la mujer en un cine artístico, alternativo y de tendencia política feminista. Entendido/Asumido su cine como elemento plástico, la artista explorará de forma paralela la experimentación matérica y física a través de los cuerpos filmados así como de la propia materialidad de la película, excluyendo toda posibilidad narrativa, dramática e ilusoria de proyección del espectador en el espacio cinematográfico y el espacio privado del creador.

Palabras clave: cine; cuerpo; biografía; identidad; mujeres
\end{abstract}

\section{Introducción}

Si el cine pudiera convertirse en plena autobiografía, ¿qué sería del trabajo del actor? Quizás éste se viera reducido a la "vivencia" real, a la plasmación de la auténtica identidad de la persona a través del filtro de la cámara. ¿Qué ocurre cuando el productor, director, guionista, actor y montador de una película coinciden? ¿Qué ocurre cuando no hay voluntad de actuar ante la cámara, sino de tratar el celuloide como elemento plástico, físico, imagen formada a partir de una materia concreta? A este respecto existen dos

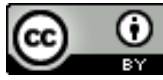

Esta obra está sob licença Creative Commons. 
fisicidades básicas con que experimentar: la establecida por los cuerpos que se sitúan ante la cámara durante la filmación; y la de la propia película en sí, materia fotosensible. Ambas están sujetas, eso sí, a la distorsión. A la de las propias limitaciones del medio utilizado y a la planteada por el artista, la de la imaginación (en el sentido de generación de imagen). Todo cuerpo físico es también imagen; al contrario, toda imagen se soporta en, es, o deriva de cuerpos físicos. Este debate sobre la materialidad fílmica ha sido abordado por numerosas autoras, como Laura Marks (2000) o Vivian Sobchack (2004).

Llegados a semejante punto, el actor se convierte en creador, y el creador en actor, pues la primera persona llena por completo la capacidad de la cámara de erigirse en pincel, en el sentido de herramienta material con la que / medio con el que plasmar aspectos de la realidad y de la identidad humana no sujetos a ninguna narrativa de la verosimilitud, de la representación de personajes ficticios, actuados ante la cámara en apartes del mundo real. La cámara se situará como artefacto que interfiere directamente en la realidad, asumiendo y alterando al mismo tiempo lo que acontece ante ella. Por tanto, ya no habrá únicamente una representación, sino una captación de acciones ante la cámara, o, como afirma Lauretis "[...] de esta forma, en la vida, en la existencia práctica, en nuestras acciones, nos representamos a nosotros mismos. La realidad humana es esta doble representación en la que somos a la vez actores y espectadores: un 'happening' gigantesco, si queréis" (Teresa LAURETIS, 1991, p. 84.).

Existen pocos ejemplos de semejante acercamiento al cine como medio artístico y de exploración personal, pero sin duda Carolee Schneemann es uno de los más representativos. En este artículo pretendemos acercarnos a su obra cinematográfica utilizando como eje principal su película Fuses (1964-1967), siempre en relación al resto de su obra, al contexto histórico en que se sitúa y a las posibles conexiones que se puedan establecer con otras obras, teóricas y fílmicas, asociadas a la representación y re-creación de la identidad femenina en el cine. A partir de lo en ella planteado, haremos un análisis de las posibilidades del cine como medio con el que construir una visión alternativa de la mujer, delante (cuerpo filmado) y detrás (sujeto a cargo de la filmación) de la cámara. La obra de Schneemann supone a este respecto un hito en cuanto a un acercamiento artístico, anti-narrativo, anti-industrial y, finalmente, anti-patriarcal, al medio cinematográfico.

\section{Mujeres y cine}

"[...] If you are a woman (and things are not utterly changed) they will almost never believe you really did it" (Carolee SCHNEEMANN, 1997, p. 61).

Un somero acercamiento a los conceptos de mujer y cine deriva con facilidad hacia la activación de la memoria y el recuerdo de un sinfín de actrices, estrellas de la gran pantalla. Sin embargo, a poco que profundicemos, entenderemos la complejidad del papel de las mujeres en la historia del cine, tradicionalmente relegadas precisamente a eso, imagen en la misma, sujeto pasivo con un control ínfimo de los engranajes de escritura, producción o dirección cinematográficos. Excluidas a la sombra en los puestos de mando, su papel principal sería el de actriz, en la mayor parte de los casos asociada a roles construidos y entregados por completo desde una óptica masculina, coherente y derivada del control patriarcal de los mecanismos de poder de la industria a ella asociada. Como actrices, las mujeres, a lo largo de la historia del cine, se vieron relegadas a dos papeles fundamentales, ambos pasivos: madre protectora, excluida en lo doméstico, el territorio de la casa; o bien sujeto de deseo, cuerpo erotizado relacionado con aspectos malignos o de poca confianza (avaricia, violencia...), personificados en uno de los tipos cinematográficos más expandidos, sobre todo en el género negro: 'la mujer fatal'. Las mujeres han sido 
utilizadas habitualmente en el cine como signo o significante, habitualmente estudiados desde la óptica de la semiótica, como elemento de significación dentro de un lenguaje superior por completo ajeno al control de la misma (Annette KUHN, 1991, p. 52).

Son pocos los ejemplos de mujeres creadoras, guionistas o directoras, y los que aparecen lo hacen a la sombra de personajes masculinos, o cumpliendo un rol que podríamos denominar masculino, y en ningún caso asociado a actitudes femeninas o comprometidas con la defensa de papeles más activos para las mujeres. Los casos de Leni Riefendstahl o de Thea von Harbou serían más que significativos a este respecto.

Existen pocos precedentes de mujeres cineastas que no puedan analizarse como reproductoras de roles masculinos en un sistema por completo patriarcal. Quizás el más significativo, y que nos va a servir de precedente directo al análisis de la obra de Carolee Schneemann, lo tengamos en Maya Deren. Maya Deren, entre los años 40 y 50, sí consiguió realizar un cine diferente, en todos los casos en películas de corta duración y explorando narrativas experimentales. Como precedente fundamental del cine femenino y artístico posterior, Deren va a establecer algunos puntos muy significativos que, posteriormente, seguirán otras artistas-cineastas a partir de los años 60-70. Por un lado, su narrativa huirá de la lógica comercial, por otro, será muy habitual la utilización de su propio entorno, su propio cuerpo y rostro, incluso podríamos decir que su identidad va a dejarse traslucir al otro lado de la cámara.

Todas estas licencias, tan poco habituales, por no decir imposibles de encontrar, en el cine comercial (recordemos que justo esos años son los de la llamada época dorada del cine clásico estadounidense), son puestas en práctica por Deren gracias a su control total sobre el producto planteado. Deren será productora, guionista, directora, fotógrafa y protagonista de sus filmes. De esta manera, Deren es ejemplo pionero, y en parte desconocido, de lo que ha venido a denominarse 'cine de autor', con una intención estético-artística prioritaria, ajeno a los circuitos comerciales. La propia cineasta va a plasmar estas ideas en escritos teóricos en que defiende el uso creativo y libre del cine como medio de expresión (DEREN, 1946, 1960).

\section{Cine como autoblografía}

El precedente de Deren nos pone sobre aviso de uno de los mecanismos fundamentales de huida de las garras del cine comercial, la utilización del mismo como medio autobiográfico, asociado a vivencias personales. En este tipo de cine se hace muy difícil separar persona y personaje, ya que el nivel de actuación del segundo se reduce al mínimo, asociándose de esta manera a una cierta vertiente de perspectiva documental.

El cine artístico siempre estuvo más asociado a esta corriente al entenderse como producto al servicio de la expresión estético-personal del autor. Será, no obstante con la reducción de precio y la aparición y extensión de equipos de pequeño formato como el Super-8, y posteriormente el vídeo, cuando se multipliquen las posibilidades de realizar cine a un nivel amateur, artístico, experimental o privado, al abaratarse considerablemente los costes de cámaras, película o proyectores.

El cine se convierte así en una autoconstrucción, liberada de un engranaje superior capaz de coordinar al enorme número de técnicos necesarios para solventar una gran producción. Comienzan a aparecer, de este modo, ejemplos de un cine alternativo, entendido como diario personal, incluso como cuaderno de bocetos en el sentido de medio de captación de imágenes aleatorias desde un punto de vista formal y estético, no siempre narrativo.

Jonas Mekas será a este respecto un personaje fundamental en el desarrollo de un cine entendido como diario, siendo un referente indispensable en la conformación de una 
vanguardia cinematográfica con núcleo en la ciudad de Nueva York. En 1969 culmina su proyecto Walden: Diaries, Notes and Sketches, pionero en esta concepción del cine entre el documento personal y el experimento visual. Mekas será, junto a Deren, aunque con una mucho mayor cercanía en el tiempo y el espacio, otro de los pilares-referentes clave en el entendimiento del cine de Schneemann, cine que podría entenderse dentro de esa corriente de vanguardia surgida en el momento (MEKAS, 1975).

\section{Cine como medio artístico}

Una de las peculiaridades clave a la hora de entender el cine de Carolee Schneemann va a provenir de su relación directa e inseparable con otras técnicas artísticas. Schneemann a este respecto no utiliza simplemente el cine con intenciones artísticas, aunque atendiendo a las posibilidades del medio como tal, sino que utilizará el mismo sin distinción con los otros medios que utilizará a lo largo de su carrera: pintura, dibujo, teatro, performances, instalaciones... Su obra, a pesar de su diversidad, podría ser calificada como la búsqueda constante de una 'pintura cinemática', la procura del movimiento en la imagen plástica en un amplio sentido de los términos (Robin BLAETZ, 2007).

Para Schneemann todas las técnicas son inseparables, están profundamente interconectadas, pues se afirman como medios con los que explorar la imagen, la generación de la misma, la captación de la misma a partir de su conformación en el tiempo y en el espacio, en el tablero que supone el mundo real, habitado, físico, generado por cuerpos que componen, cómo no, e inevitablemente, imágenes. Su entendimiento de arte y realidad está muy asociada a uno de los grandes grupos artísticos del momento: fluxus, con el que tuvo una intensa relación. Fluxus fue un movimiento internacional de difícil definición, en el que creadores de muy diversa procedencia se empeñaron en defender una creación libre e interdisciplinar donde el azar y lo cotidiano se elevan a categoría artística (Owen F. SMITH, 1998). Según esta corriente, arte y vida se interrelacionan, borrándose cualquier posibilidad de distinción entre ambos. Schneeman, no obstante, va a adaptar y desarrollar estas ideas desde su peculiar perspectiva, atendiendo tanto a lo físico como lo formal, pues, según ella, todo cuerpo físico genera imagen, y toda imagen está compuesta por elementos matéricos, físicos.

La imagen en el arte de Schneemann no se ve reducida de este modo a la mera superficie, sino que esa superficie adquiere profundidad debido a la importancia concedida a su fisicidad. No es sólo apariencia, sino la materia / es la esencia asociada a todo cuerpo. La representación en el cine de Schneemann no adquiere pues un carácter dramático sino físico: es la presentación física (en celuloide) de aquellos cuerpos que hubo ante la cámara en el momento de la filmación. De este modo, representar, para Schneemann, es volver a presentar físicamente los cuerpos captados primeramente con la simple añadidura de otra capa matérica (la película). Capa sujeta, eso sí, a alteraciones como superposiciones, quemados, tintados, collages, que aumentan si cabe, el carácter material del cine.

Schneemann rehuye de la utilización de metáforas o símbolos que se refieran a referentes lejanos, de la intención lingüística de envío al receptor de un significado cerrado. Por un lado, la autora pasa a convertirse en sujeto activo, conformadora de imágenes físicas, en movimiento, en un proceso físico siempre abierto. Por otro lado, aparecerá como cuerpo protagonista en sus filmes, performances, pinturas... De este modo, la artista aúna y destruye la posible separación entre roles activos y pasivos asociados al papel de la mujer en la historia del arte y del cine tradicional, adquiriendo un control total, como hacía, recordemos, Deren, sobre el proceso de realización de sus obras.

De la mano de Schneemann (así como de Deren y de tantas otras) el rol de las mujeres como elementos pasivos queda superado, pero no negándolo a partir de su 
supresión como objetos, sino retomando el valor de su corporeidad; no como algo construido desde el exterior, sino asumido y planteado por las propias mujeres. Solo así las mujeres cineastas pueden afirmarse como sujetos (directoras) y objetos (actrices) desde un punto de vista positivo. Sin embargo, el rol de actriz va a adquirir nuevos matices, pues no se basará en ningún caso en una actuación, en el sentido dramático-teatral del término, ante la cámara. De este modo, la actriz se ve liberada de la tentativa de reproducción de un rol ajeno al servicio de perspectivas dictadas por el orden (patriarcal) establecido, sino que afirmará una identidad propia, su intimidad, inseparable de ésta, y, aún más, su cuerpo, ya no sometido a mandatos externos, reprimido y re-presentado como imagen superficial, sino afirmado en su realidad, en su corporeidad.

\section{Fuses}

Después de todo lo planteado hasta el momento, podríamos caer en la tentación de analizar un gran número de obras de Carolee Schneemann. Vamos, no obstante, a tratar de centrarnos en un punto clave de la misma, la producción del film Fuses (1964-1967), obra que de algún modo concentra un gran número de los elementos clave a la hora de comprender los objetivos de la artista respecto a la relación de la obra con la construcción de la imagen de la mujer.

Fuses, más allá de un visionado plano, guarda un enorme número de factores ocultos que han hecho, si cabe, crecer en el tiempo su importancia en la historia del cine, como hito del cine artístico y de compromiso social, político, y, aún más, estético-formal. Fuses es parte de una compleja exploración formal y conceptual, imposible de simplificar, debido sobre todo a un montaje en múltiples capas, a la utilización del celuloide como superficie no sólo documental, sino de construcción de imagen en un amplio proceso previo y posterior a la propia filmación [Fig.1]. Además Fuses es,

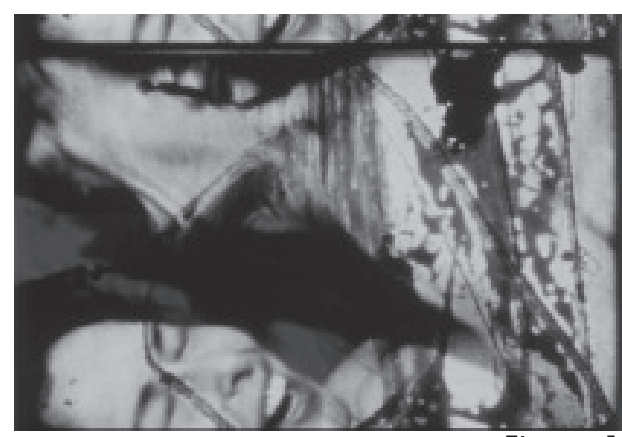
más allá de lo formal, un desafío a los roles establecidos en la experiencia del arte, a las relaciones entre el creador y el espectador (BLAETZ (Ed.), 2007, p. 105).

Como experiencia cinematográfica, Fuses supone la culminación de los experimentos artísticos de Schneemann, emprendidos con un objetivo claro: incluir la experiencia temporal en la imagen. De ahí que resulten fáciles de entender los pasos progresivos realizados por la artista de pintura a teatro y performance, para terminar optando por el cine como medio que suponía la conjunción de las posibilidades de todos los anteriores. Como superficie física, además, la película puede concebirse como un lienzo en que al sucederse una tras otra las imágenes, sucesivamente, se genera una sensación de 'cinetismo' movimiento en su visionado [Fig.2]. Estas imágenes, por separado, fotograma a fotograma, podrían ser analizadas como pictóricas, o muy similares a las pictóricas.

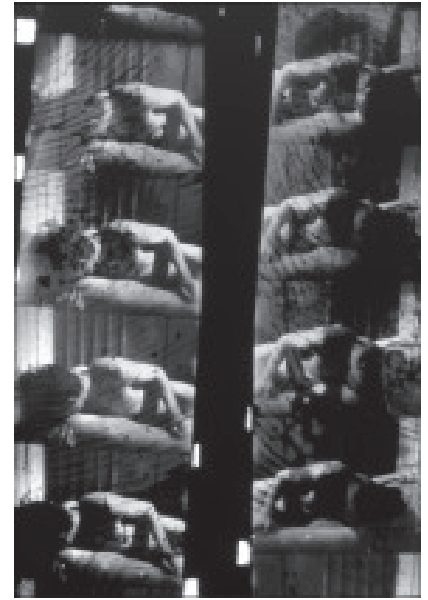

Figura 2 
Schneeman se ayuda para ello, en contraposición a las posibilidades de otros medios como las performances, desarrolladas en eventos públicos, de la intimidad otorgada por los propios métodos de visualización del cine. Así, el cine de Schneemann aprovecha la posibilidad de experimentación individualizada, solitaria e íntima del espectador, para mostrarle de ese modo el entorno privado de la artista de una forma apropiada.

Schneemann, de la mano de Fuses, consigue alcanzar varios objetivos de difícil consecución. Hace posible la visibilización pionera en la historia del cine de aspectos habitualmente ocultos al espectador: por un lado la película, el celuloide, se hace visible, no es transparente, ni una simple ventana imaginaria a un espacio ilusorio, sino que se convierte en medio material capaz de ser captado por el ojo. Por otro, muestra otro aspecto tradicionalmente invisible: el ámbito doméstico, la intimidad y privacidad de la artista. Pero la mostración de este ámbito subvertirá por completo el habitual prejuicio, tan extendido por el cine narrativo y resto de medios, de lo doméstico como lugar de reclusión, de realización de los quehaceres al servicio de la familia tradicional. En este caso, Schneemann muestra que la casa, el hogar, puede ser un lugar no represivo para la mujer, sino un espacio de placer y relaciones igualitarias entre sexos. Consigue, así, utilizar la cámara como medio de visibilización, de hacer 'visible lo invisible' (KUHN, 1991, p. 87), un modo de denuncia en sí mismo al dar luz a aspectos interesadamente ocultos o rechazados por los mecanismos del poder.

La pretendida huida de la ilusión narrativa y espacial del cine de Schneemann se hace aún más evidente en su exclusión de un elemento dramático por excelencia en el cine comercial: el sonido. La ausencia de todo sonido (musical o ambiental) va a multiplicar otro hecho fundamental en su recepción por parte del espectador: la incapacidad del mismo de abandonarse en su visionado. La posibilidad de proyección en el espacio fílmico es negada, y el espectador mantendrá y será consciente durante toda la proyección de su propia fisicidad. El público no se diluye en el aparte que le ofrece el espacio fílmico, sino que experimenta lo ofrecido por la artista sin perder la sensación física de su cuerpo, aumentada si cabe por la incomodidad del silencio otorgado a la visualización voyeurística de un espacio ajeno, de la intimidad de otras personas.

Con todo ello, el choque que produce Fuses es obvio, aún más si atendemos a un público estándar asociado a la visualización del cine como ocio. Schneemann excluye en su planteamiento la búsqueda de la empatía. Tanto es el choque, que la película se hace incluso complicada de ver debido a su caótico montaje, a la utilización de planos detalle y desenfoques, y a la manipulación posterior del filme. Tan compleja es la recepción de Fuses, que ni tan siquiera sería bien acogida en su momento por sus posibles más interesadas receptoras: las asociadas a movimientos políticos, teóricos y artísticos feministas.

Schneemann consigue romper con ella con cualquier prejuicio, acercándose a la mostración del sexo, el cuerpo femenino y la intimidad de la artista como nunca antes lo había hecho ninguna otra. Schneemann naturaliza el sexo y su visionado, rompiendo con toda posibilidad de construcción de una película erótica en el sentido tradicional del término [Fig. 3]. El espectador que

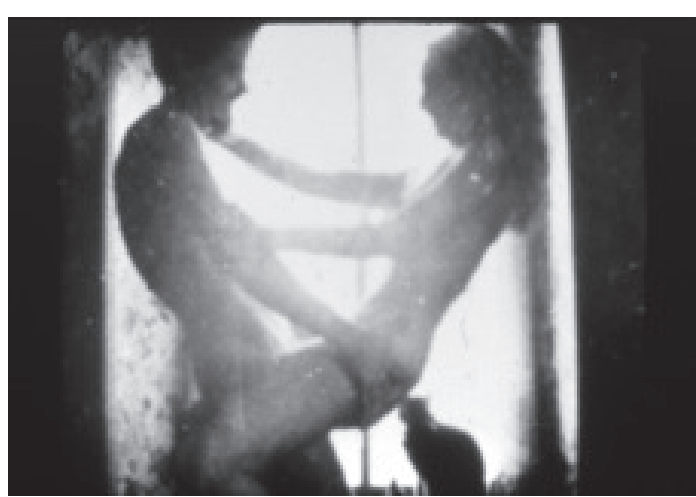

Figura 3

1454 Estudos Feministas, Florianópolis, 25(3): 1449-1458, setembro-dezembro/2017 
busque una excitación o placer no verá recompensado sus objetivos, pues la inmersión dramática, escenográfica y ficticia construida en el cine comercial será imposible, debido sobre todo, a la consciente carga matérica de la propia película.

Fuses es una película que muestra sexo explícito de un modo 'antipornográfico', en palabras de la propia autora (SCHNEEMANN, 2001, p.183). Es un viaje a un mundo artístico que es inseparable de su persona y su identidad. Muchos acusaron a la artista de narcisismo y egocentrismo, acusaciones simplificadoras que no se sostienen desde el conocimiento adecuado del contexto y la obra. La artista es la actriz, personaje principal de su propia vida, por lo que se convertirá en protagonista obligada de su obra, por coherencia y cercanía, así como por continuación directa de sus intereses formales, estéticos y políticos.

En su película, el cuerpo femenino no es objeto pasivo de admiración con el objetivo de generar un deseo erótico, no está idealizado, sino al contrario, es un cuerpo femenino desnudo naturalizado, más allá de todo tabú, y por completo ajeno a la perspectiva generada desde la sumisión a los deseos del espectador masculino. Aún más, cuerpo femenino y masculino se muestran de modo igualitario, no sujetos a relaciones de poder, $\mathrm{ni}$ con fines narrativos o dramáticos que pudieran llevar el relato a mensajes ulteriores. Schneeman evita toda utilización simbólica de lo mostrado, niega la posibilidad de un discurso que haga referencia a un significado ajeno al significante (SCHNEEMAN, 2001, p. 201), algo que en sí mismo subvierte el mensaje patriarcal dominante en el cine comercial.

\section{Más allá de Fuses}

Fuses es coherente con la obra anterior y posterior de Schneemann, tanto plástica en general, como performática o fílmica. Dentro además de una trilogía autobiográfica que completan Plumb Line (1968-1971) y Kitch's last meal (1973-1976). Ambas películas ahondan en los temas tratados de manera pionera en Fuses: la filmación y mostración de aspectos privados, espacios y relaciones íntimas, etc. La fisicidad del material cinematográfico y la imposibilidad de la inmersión en él continuará en ambas películas: incluyendo nuevas soluciones técnicas, desde la partición del plano hasta su disolución última tras su quemado.

Estas primeras obras fílmicas de Schneemann podrían considerarse como protofeministas, ya que exponen un buen número de aspectos asociados a las teorías sobre la posición política, social y artística de la mujer, incluso antes de la estructuración de las mismas de una forma coherente y cohesionada. Sin embargo, debemos entender los hallazgos de Schneemann dentro de un contexto artístico muy dinámico, donde es posible encontrar un gran número de artistas experimentando con aspectos similares. Poco tiempo después, artistas como Valie Export o Barbara Hammer añadirán nuevas cuestiones a las planteadas por Schneemann en sus investigaciones cinematográficas sobre la subjetividad y la identidad sexual. Valie Export, en sus performances y películas, buscará directamente la confrontación, la polémica y la reacción directa del público. Hammer buscará, por su parte, añadir aspectos relacionados con una visión lésbica del sexo y el papel de la mujer a sus experimentaciones fílmicas. Ambas utilizarán recursos cinematográficos radicales para forzar la reflexión del espectador al visualizar aspectos habitualmente rechazados u obviados por el cine tradicional. Export en filmes como Mann \& Frau \& Animal (1972) o Hammer en Multiple orgasm (1976), ofrecerán el visionado en primerísimo primer plano del sexo femenino y de un placer por completo ajeno a la experiencia masculina, defendiendo así una autonomía total, estética y sexual, de la mujer.

La visión del sexo femenino en estos filmes puede ponerse en relación con los planteamientos teóricos de Julia Kristeva y su aproximación al feminismo desde una 
perspectiva psicoanalítica. Kristeva defenderá el territorio de lo íntimo asociado a aspectos psicoanalíticos y a la resistencia política (KRISTEVA, 2001) como aquello que, al mostrarse, llega a alcanzar un status monstruoso (en el sentido etimológico de la palabra), asociado a lo obsceno (lo fuera de escena, fuera del campo cinematográfico en este caso) y abyecto (KRISTEVA, 1980). En todos los casos, semejante cine feminista, en su visibilización de aspectos ocultos y rechazados por la tradición patriarcal, alcanzará tintes subversivos y, en sí mismos, opuestos al orden establecido, generando no el placer, sino abiertamente la incomodidad y el disgusto del espectador de la mano de la explicitación de los aspectos más indecorosos y ocultos del cuerpo femenino (la menstruación, la sangre, los fluidos...).

Y es que va a ser a partir de los años 70 cuando se generalice la reflexión y se sucedan las teorías sobre las relaciones de la mujer y el cine, tratando de recuperar su papel forzosamente clandestino o secundario en el mismo en la historia hasta ese momento, y planteando las opciones de consecución de un cine feminista, o bien de lo que podríamos denominar de 'sensibilidad femenina'. Este hecho se hace especialmente notable desde finales de los años 70 en algunos puntos de la geografía europea. De estas décadas clave, años 70 y 80 , proceden algunos de los textos clásicos, irremplazables, y más influyentes al respecto: los textos de Claire Johnston, de Sharon Smith, Laura Mulvey, Teresa de Lauretis, las teorías de Kristeva...

\section{Conclusiones}

A pesar de los avances obtenidos desde aquellos tiempos pioneros, aún a día de hoy puede analizarse la desigualdad del papel de la mujer en una industria como la cinematográfica. Aunque es posible encontrar un buen número de mujeres cineastas con una reconocida trayectoria, gran parte de las mismas lo harán asumiendo un posicionamiento heredado, por lo que su cine no podrá en ningún caso distinguirse del realizado por hombres: tal podría ser el caso de la cineasta Kathryn Bigelow, flamante ganadora del OSCAR a mejor directora por su filme bélico En Tierra Hostil (The Hurt Locker, 2008).

Sólo el cine artístico y por completo independiente de los mecanismos de la industria continúa las experimentaciones abiertas desde los años 60 y 70 . Y a artistas como Schneemann, Export, Hammer, Ana Mendieta, Hannah Wilke, Martha Rossler o Mona Hatoum se han ido incorporando a cuentagotas a lo largo de este tiempo muchas otras, aunque como decimos, en gran parte de los casos a través de producciones alternativas, grabaciones en formato casero y distribución y visualización reducidos a circuitos undergrounds, museos de arte contemporáneo, seminarios, ciclos... Sólo algunas excepciones, como son los casos de Agnés Vardá o Chantal Akerman, pueden situarse en un territorio intermedio entre el cine de autor, aunque con distribución comercial más o menos amplia, y el cine artístico. Tendremos que seguir pues esperando la llegada de una vía femenina generalizada al cine comercial, verdadero medio de masas, pues sólo en ese momento, entendido como un espejo social, podremos entender que el cine refleje una igualdad y normalizada relación entre géneros derivada de la alcanzada en la sociedad.

Si el ámbito doméstico era el reservado tradicionalmente a la mujer por el poder patriarcal, parece evidente que, ya tan sólo el acceso a la tecnología por parte de la misma supone toda una oportunidad de reescritura de su papel social. Algunas teorías han llevado la utilización de esta tecnología al extremo, además desde puntos de vista radicalmente feministas, tal es el caso de la teoría cyborg defendida por Donna Haraway (1995). En territorios más pragmáticos, podríamos señalar que el cine, en manos de cualquier grupo social, es un arma de lucha de gran alcance, pues es abiertamente utilizado como

1456 Estudos Feministas, Florianópolis, 25(3): 1449-1458, setembro-dezembro/2017 
herramienta para escribir la Historia y contar historias, que repetidas una y otra vez, se naturalizan hasta convertirse en verdad. Todo una máquina generadora de realidad al servicio del ser humano. Si el género es una construcción cultural y tecnológica (según teorías de largo alcance como las de Foucault), puede ser reescrito de la mano de técnicas como el cine.

Pero más allá de las mayúsculas y las grandes palabras, quizás el cine, antes de nada, pueda servir para analizar y reflexionar sobre ámbitos más cercanos: el de nuestras propias relaciones diarias con los demás y con nosotros mismos, convertido así en método de autorreflexión y, por qué no, autoconstrucción. Tal y como muestra Schneemann, el cine puede ser una herramienta autobiográfica que nos ayude a entender nuestro papel en el mundo, nuestras relaciones con el medio ambiente y con los otros seres humanos. Convertido todo hombre/mujer en actor/actriz de su propia vida, y convertido su cuerpo, necesariamente, en su pincel.

\section{Referencias}

ALBIZU, Natalia. "Mujeres irrepresentable. La crítica feminista a la narratividad cinematográfica clásica". Bajo Palabra, n.5, p. 131-140. 2010.

BLAETZ, Robin (Ed.). Women's experimental cinema: critical frameworks. Durham: Duke University Press, 2007.

CABALLERO, Alberto. "La mujer, la mujer-artista, el arte (el objeto)". Escáner Cultural: Revista virtual de arte contemporáneo y nuevas tendencias. n. 10, p. 103, 2008. Disponible en: http://revista.escaner.cl/node/706. Acceso el: 15/06/2015.

CARRO FERNÁNDEZ, Susana. Mujeres de ojos rojos. Del arte feminista al arte femenino. Gijón: Trea, 2010.

COLAIZZI, Giulia. La pasión del significante: teoría de género y cultura visual. Madrid: Biblioteca Nueva, 2007.

CRUZADO RODRÍGUEZ, Ángeles. Mujeres y cine: discurso patriarcal y discurso feminista de los textos a las pantallas. Sevilla: Arcibel, 2009.

DEREN, Maya. An anagram of ideas on art, form and film. Alicat Book Shop Press, 1946.

DEREN, Maya. "Cinematography: the creative use of reality". Daedalus, v. 89, n. 1, p. 150 167. 1960.

DYER, Richard. Stars. London: British Film Institute, 1979.

HARAWAY, Donna J. Manifiesto para cyborgs: ciencia, tecnología y feminismo socialista a finales del siglo XX. Valencia: Universidad de Valencia, Centro de Semiótica y Teoría del Espectáculo, 1995.

JOHNSTON, Claire (Ed.). Notes on women's cinema. London: Society for Education in Film and Television, 1973.

KRISTEVA, Julia. Pouvoirs de l'horreur: essai sur l'abjection. Paris: Éditions du Seuil, 1980.

KRISTEVA, Julia. La revuelta íntima: literatura y psicoanálisis. Buenos Aires: Eudeba, 2001. KUHN, Annette. Cine de mujeres: feminismo y cine. Madrid: Cátedra, 1991.

LAURETIS, Teresa. Alicia ya no: feminismo, semiótica y cine. Madrid: Cátedra, 1991.

MARKS, Laura U. The skin of the film: Intercultural cinema, embodiment, and the senses. Duke: University Press, 2000.

MAYER, Sophie y OROZ, Elena (Eds.). Lo personal es político: feminismo y documental: una compilación de ensayos sobre documental y feminismo. The personal is political: feminism and documentary: a compilation of essays on documentary and feminism. Pamplona: Gobierno de Navarra, Instituto Navarro de las Arte Audiovisuales y la Cinematografía, 2011. 
MEKAS, Jonas. Diario de cine: (el nacimiento del nuevo cine americano). Madrid: Fundamentos, 1975.

PARRONDO, Eva. "Feminismo y cine: notas sobre treinta años de historia". Secuencias, n. 3, p. 9-20. 1995.

SANGRO, Pedro y PLAZA, Juan F. (Eds.). La representación de las mujeres en el cine y la televisión contemporáneos. Barcelona: Laertes, 2010.

SCHNEEMANN, Carolee. More than meat joy: performance works and selected writings. Nueva York: McPherson \& Co, 1997.

SCHNEEMANN, Carolee. Imaging her erotics: Carolee Schneemann: essays, interviews, projects. Cambridge: Mass. MIT Press, 2001.

SCHNEEMANN, Carolee y WALLACE, Brian. Within and beyond the premises. Nueva York: Samuel Dorsky Museum, 2010.

SMITH, Owen F.. Fluxus: The history of an attitude. San Diego: San Diego State University Press, 1998.

SOBCHACK, Vivian. Carnal thoughts: Embodiment and moving image culture. Berkeley: Univ. of California Press, 2004.

[Recebido em 22/08/2015,

reapresentado em 10/05/2016

e aprovado em 25/05/2016]

Carolee Schneemann. Cinema as Autobiography, the Artist as an Actress, the Body as a Brush

Abstract: This paper analyzes the relationship between cinema and women from the film work of Carolee Schneemann, mainly from her autobiographical work Fuses (1964-1966). In this study, we discuss the role the artist plays as producer, director and main protagonist of all her production. We reflect on the role of the creator-director as an actor that would lead to the achievement of a film with necessarily autobiographical overtones. Assuming the avant-garde perspective of the cinema as a personal diary, Schneemann's cinema will explore different aspects of identity and sexuality of women in an artistic, alternative and politically feminist cinema. Understanding her cinema as a plastic element, the artist will explore at the same time a physical and matteric experimentation through the filmed bodies as well as the very materiality of the film, excluding any narrative, dramatic and illusory chance of projection of the spectator in both the cinematic and the private space of the artist.

Key words: Cinema; Body; Biography; Identity; Women

María Barbaño González-Moreno (barbaniogonzalez@gmail.com) es doctora por la Universidad de Granada. Tesis: "Fotografía, mujer e identidad: imágenes femeninas en la fotografía desde finales de los 60 ". Sus intereses principales de investigación están centrados en la fotografía y los estudios de género, especialmente en el uso de la imagen del cuerpo femenino por parte de las mujeres artistas. También en temas como la inclusión de mujeres en las colecciones de la institución museística.

Luis D. Rivero Moreno (luisda@ugr.es) es docente e investigador en el Departamento de Historia del Arte de la Universidad de Granada. Miembro del grupo de investigación "HUM-736. Tradición y Modernidad en la Cultura Artística Contemporánea". Sus principales temas de investigación se centran en el estudio de la representación humana en el arte contemporáneo, así como temas relacionados con la sociología, filosofía del arte y las relaciones de arte y tecnología en la sociedad digital. 